\title{
Laparoscopic Stapled Gastrojejunostomy in Non-operable Cases of Malignant Gastric Outlet Obstruction (GOO): A Retrospective Study
}

\author{
Hilal A Makhdoomi ${ }^{1}$, Tajamul Rashid ${ }^{2}$, Irfan N Mir ${ }^{3}$, Suhail N Bhat ${ }^{4}$, Asifa Azad ${ }^{5}$
}

\begin{abstract}
Background: Inability of gastric contents to go beyond the proximal duodenum is termed as gastric outlet obstruction (GOO). This may be partial or complete. A multitude of causes, benign/malignant, may lead to GOO of gastric and extra gastric origins. Malignant GOO is a common condition among locally advanced gastric cancer patients. One of the relative contraindications for surgery is the presence of advanced malignancy; in these cases, in which life expectancy may be limited to a few months, palliative surgical measures may improve the quality of life. The role of the laparoscopic approach in the treatment of GOO is under investigation and may represent a valid form of therapy with low morbidity.

Materials and methods: This was a retrospective study conducted in the Department of General Surgery, Government Medical College, Srinagar, from May 2018 to May 2019. A total of 35 patients who were diagnosed as cases of non-operable malignant GOO were included in the study. All patients underwent laparoscopic stapled gastrojejunostomy after diagnostic laparoscopy. This study was aimed at operative time, time for making anastomosis, hospital stay, return of bowel sounds, and postoperative complications.

Results: Mean age of patients in our study was 66.8 years with male predominance. Mean operative time was 94.35 minutes with a mean time of 20.4 minutes for making stapled anastomosis. Mean hospital stay, return of bowel sounds, and resumption of orals were 7.9, 2.28, and 3.85 days, respectively. Bleeding from the anastomotic site was noted in three patients and anastomotic leak was noted in one patient.

Conclusion: Laparoscopic stapled gastrojejunostomy is a viable option for palliation in advanced cases of non-operable malignancies leading to GOO. It is associated with less operative times and less immediate postoperative complications. However, further studies are needed before laparoscopic stapled gastrojejunostomy is taken up as a standard for non-operable cases of malignant GOO.

Keywords: Gastric outlet obstruction, Gastrojejunostomy, Palliation, Diagnostic Laparoscopy.

World Journal of Laparoscopic Surgery (2021): 10.5005/jp-journals-10033-1427
\end{abstract}

\section{INTRODUCTION}

Inability of gastric contents to go beyond the proximal duodenum is termed as gastric outlet obstruction (GOO). It is a misnomer encompassing numerous cases of gastric or extra-gastric disease, rather than an isolated gastric disease. It may be partial or complete. ${ }^{1-3}$ The incidence of GOO is not precisely known. The major cause of GOO was peptic ulcer disease (PUD) till the discovery of proton pump inhibitors and Helicobacter pylori, which has resulted in fewer cases of PUD presenting with GOO $(<5 \%)$. In the modern era, the major cause is known to be malignancy, especially in the developed world. ${ }^{4}$ The prevalence of peptic ulcer and gastric carcinoma are 8 and $3 /$ lakh, respectively. ${ }^{5}$ Malignant GOO is a clinical symptom of advanced malignancies in the upper gastrointestinal tract, most commonly gastric and pancreatic malignancies. Palliative treatment is required for patients with unresectable primary malignancies or metastatic lesions. Despite a decrease in the incidence of gastric cancer over previous decades, gastric cancer remains the fourth most common malignant disease and the second main cause of cancer-related death worldwide. ${ }^{6}$ Even if the patient has unresectable disease, palliative surgical measures may improve the quality of life. In GOO, bypass (gastrojejunostomy) can be performed by both open and laparoscopic techniques. The role of the laparoscopic approach in the treatment of GOO is under investigation and may represent a valid form of therapy with low morbidity.

\begin{abstract}
1,4Department of General Surgery, Government Medical College, Srinagar, Jammu and Kashmir, India

${ }^{2}$ Department of General Surgery, Hamdard Institute of Medical Sciences and Research, New Delhi, India

${ }^{3}$ Department of Surgery, SKIMS, Srinagar, Jammu and Kashmir, India

${ }^{5}$ Department of Unani Medicine, Asian Institute of Medical Sciences, Srinagar, Jammu and Kashmir, India

Corresponding Author: Tajamul Rashid, Department of General Surgery, Hamdard Institute of Medical Sciences and Research, New Delhi, India, Phone: +91 7006473796, e-mail: doc.tajamul@gmail.com How to cite this article: Makhdoomi HA, Rashid T, Mir IN, et al. Laparoscopic Stapled Gastrojejunostomy in Non-operable Cases of Malignant Gastric Outlet Obstruction (GOO): A Retrospective Study. World J Lap Surg 2021;14(1):43-45.
\end{abstract}

Source of support: Nil

Conflict of interest: None

\section{Materials and Methods}

This was a retrospective study conducted in the Department of General Surgery, Government Medical College, Srinagar, from May 2017 to May 2019. A total of 35 patients of both sexes in the 
age group of 30 years and above, who were diagnosed as cases of malignant GOO, were included in the study. All patients underwent laparoscopic stapled gastrojejunostomy after diagnostic laparoscopy by a single surgical team. Patients who were found to have resectable growth after diagnostic laparoscopy were excluded from the study. Informed and written consent was taken prior to the performance of each procedure. Ceftriaxone injection of $1 \mathrm{gram}$ was given to all patients at the time of induction of anesthesia.

With the patient in supine position, three ports were used. A $12 \mathrm{~mm}$ port was placed $2 \mathrm{~cm}$ below right costal margin in midclavicular line for staplers. Second, $10 \mathrm{~mm}$ port (camera port) in midclavicular line was placed $5 \mathrm{~cm}$ below the first port. Third, $5 \mathrm{~mm}$ port was placed $5 \mathrm{~cm}$ below the second port in the midclavicular line. Diagnostic laparoscopy with staging was done. If the staging favored unresectable growth, laparoscopic stapled gastrojejunostomy was done. The study was aimed at total operative time, time for making anastomosis, hospital stay, return of bowel sounds, and postoperative complications.

\section{Results}

Mean age of patients in our study was 66.8 years with male predominance (Tables 1 and 2). Mean operative time was 94.35 minutes with a mean time of 20.4 minutes for making stapled anastomosis (Tables 3 and 4). Mean hospital stay, return of bowel sounds, and resumption of orals were 7.9, 2.28, and 3.85 days, respectively (Tables 5 to 7). Bleeding from the anastomotic site was noted in three patients and anastomotic leak was noted in one patient (Table 8).

Table 1: Age distribution

\begin{tabular}{llc}
\hline Age (in years) & Number of patients & Percentage \\
\hline $50-59$ & 20 & 57.14 \\
$60-69$ & 13 & 37.14 \\
$\geq 70$ & 02 & 5.72 \\
\hline
\end{tabular}

Mean age: 66.81 years

Table 2: Sex distribution

\begin{tabular}{lll}
\hline Sex & Number of patients & Percentage \\
\hline Male & 27 & 77.14 \\
Female & 08 & 22.86 \\
\hline
\end{tabular}

Table 3: Operative time

\begin{tabular}{lll}
\hline Time (minutes) & Number of patients & Percentage \\
\hline $80-95$ & 19 & 54.28 \\
$95-110$ & 16 & 45.72 \\
$\geq 110$ & 0 & 0 \\
\hline
\end{tabular}

Mean: 94.35 minutes

Table 4: Anastomosis time

\begin{tabular}{lll}
\hline Time (minutes) & Number of patients & Percentage \\
\hline$<20$ & 30 & 85.72 \\
$20-24$ & 05 & 14.28 \\
$\geq 25$ & 0 & 0 \\
\hline
\end{tabular}

Mean anastomosis time: 20.4 minutes

\section{Discussion}

For non-operable malignancies of the stomach, duodenum, or pancreatic head with GOO, gastrojejunostomy is indicated as palliative treatment. ${ }^{7,8}$ Historically, open gastrojejunostomy used to be the only method available. Minimally invasive approaches are now more commonly preferred. In our study, we routinely followed laparoscopy as a modality for diagnosis and patients having GOO with stage 4 disease were taken up for laparoscopic stapled gastrojejunostomy. We used laparoscopic linear stapler with $60 \mathrm{~mm}$ mounted cartridge.

In our study, the mean age of patients was 66.81 years. Zhang et al. in their study of 28 patients reported an average age of 68 years (range, 25-99). ${ }^{9}$ In a study by Seo et al., the mean age of patients in stapled group was $60.1 \pm 11.7 .^{10}$ Males predominated females in our study. This finding was concurrent with studies that suggested males are more commonly affected with GOO. ${ }^{11}$ Laparoscopic gastrojejunostomy is technically more difficult than open gastrojejunostomy in creating a bypass. The mean operative time and mean time for making anastomosis in our study were 94.35 and 20.4 minutes, respectively. A study by Zhang et al. found the average operative time for laparoscopic stapled gastrojejunostomy was 170 minutes. ${ }^{9}$ Studies have also shown that operative time decreases as the individual surgeons become more experienced. ${ }^{12}$

Table 5: Hospital stay

\begin{tabular}{lll}
\hline Hospital stay (days) & Number of patients & Percentage \\
\hline 7 & 14 & 40 \\
8 & 13 & 37.14 \\
9 & 5 & 14.28 \\
10 & 3 & 8.58
\end{tabular}

Mean hospital stay: 7.91 days

Table 6: Return of bowel sounds

\begin{tabular}{lll}
\hline Days & Number of patients & Percentage \\
\hline 2 & 25 & 71.42 \\
3 & 10 & 28.58 \\
4 & 0 & 0 \\
\hline
\end{tabular}

Mean number of days for return of bowel sounds: 2.28 days

Table 7: Resumption of orals

\begin{tabular}{lll}
\hline Days & Number of patients & Percentage \\
\hline 3 & 11 & 31.42 \\
4 & 18 & 51.44 \\
5 & 06 & 17.14 \\
\hline
\end{tabular}

Mean days for resumption of orals: 3.85 days

Table 8: Immediate postoperative complications

\begin{tabular}{lll}
\hline Complication & Number of patients & Percentage \\
\hline Bleeding & 02 & 5.71 \\
Anastomotic leak & 01 & 2.85 \\
Intra-abdominal abscess & 0 & 0 \\
Fistula formation & 0 & 0 \\
\hline
\end{tabular}


In a study done by Seo et al., the time taken for creating stapled anastomosis was $5.7 \pm 0.7 .^{10,13}$ The difference in time for making stapled anastomosis in our study may be attributed to the learning curve with stapled gastrojejunostomy. The hospital length of stay can be as low as 3 days and as high as 14 days in laparoscopic gastrojejunostomy. ${ }^{10,14}$ In our study, the mean length of hospital stay was 7.91 days. The mean duration for return of bowel sounds in our study was 2.28 days. This was comparable with studies conducted by Linda et al. ( 3 days) and Seo et al. ( $2.4 \pm 0.9$ days). ${ }^{9,10}$ Resumption of oral feeds is an important predictor of a successful gastrointestinal surgery. Mean duration for resumption of oral feeds in our study was 3.85 days. Alam et al. and Kazanjian et al., both reviewed patients with GOO secondary to non-operable cancer and found the median time to solid food after laparoscopic gastrojejunostomy to be 4 days. ${ }^{15,16}$

As we know, the complications are a part of any surgery. Among various complications of laparoscopic gastrojejunostomy, we found intraoperative anastomosis site bleeding in 0 patients (11.42\%) and anastomotic leak in 01 patient (2.85\%). Intra-abdominal abscess and fistula formation were noted in none of our patients. Gonzalez et al. in their study of found intraoperative bleeding from the anastomotic site in 01 patient. ${ }^{17}$ Zhang et al. in his study mentioned a leak rate of $3.57 \%$ in his study. ${ }^{9}$

We, in our study, observed lesser complications of the procedure mentioned in the literature. This may be attributed to smaller sample size in particular. The lesser incidence of complications in our study may also be because of the fact that all the patients were properly optimized before surgery. However, further studies with a larger cohort are needed.

\section{ConcLusion}

There have been several modifications and innovations in the instrumentation available for advanced laparoscopic procedures, which have enabled surgeons to perform several procedures that would otherwise not have been feasible. Laparoscopic stapled gastrojejunostomy is one of them and is a viable option for palliation in cases of advanced cases of non-operable malignancies leading to GOO. It is associated with less operative times and less immediate postoperative complications. However, further studies are needed before laparoscopic stapled gastrojejunostomy is taken up as a standard for non-operable cases of malignant GOO.

\section{References}

1. Samad A, Khanzada TW, Shoukat I. Gastric outlet obstruction: change in etiology. Pak J Surg 2007;23(1):29-32.
2. Johnson CD. Gastric outlet obstruction malignant until proved otherwise. Am J Gastroenterol 1995;90(10):1740.

3. Tendler DA. Malignant gastric outlet obstruction: bridging another divide. Am J Gastroenterol 2002;97(1):4-6. DOI: 10.1111/j.15720241.2002.05391.x.

4. Shone DN, Nikoomanesh P, Smith-Meek MM, et al. Malignancy is the most common cause of gastric outlet obstruction in the era of $\mathrm{H} 2$ blockers. Am J Gastroenterol 1995;90(10):1769-1770.

5. Khuroo MS, Zargar SA, Mahajan R, et al. High incidence of oesophageal and gastric cancer in Kashmir in a population with special personal and dietary habits. Gut 1992;33(1):11-15. DOI: 10.1136/gut.33.1.11.

6. Carcas LP. Gastric cancer review. J Carcinog 2014;13:14. DOI: 10.4103/1477-3163.146506.

7. Stupart DA, Panieri E, Dent DM. Gastrojejunostomy for gastric outlet obstruction in patients with gastric carcinoma. S Afr J Surg 2006;44(2):52-54.

8. Gurusamy KS, Kumar S, Davidson BR. Prophylactic gastrojejunostomy for unresectable periampullary carcinoma. Cochrane Database Syst Rev 2010;(10):CD008533. DOI: 10.1002/14651858.CD008533.pub2.

9. Zhang LP, Tabrizian P, Nguyen S, et al. Laparoscopic gastrojejunostomy for the treatment of gastric outlet obstruction. JSLS 2011;15(2):169173. DOI: $10.4293 / 108680811 X 13022985132074$.

10. Seo SH, Kim KH, Kim MC, et al. Comparative study of hand-sutured versus circular stapled anastomosis for gastrojejunostomy in laparoscopy assisted distal gastrectomy. J Gastric Cancer 2012;12(2):120-125. DOI: 10.5230/jgc.2012.12.2.120.

11. Jaka H, Mchembe MD, Rambau PF, et al. Gastric outlet obstruction at Bugando Medical Centre in Northwestern Tanzania: a prospective review of 184 cases. BMC Surg 2013;13:41. DOI: 10.1186/1471-248213-41.

12. Pournaras DJ, Jafferbhoy S, Titcomb DR, et al. Three hundred laparoscopic Roux-en-Y gastric bypasses: managing the learning curve in higher risk patients. Obes Surg 2010;20(3):290-294. DOI: 10.1007/s11695-009-9914-7.

13. Navarra G, Musolino C, Venneri A, et al. Palliative antecolic isoperistaltic gastrojejunostomy: a randomized controlled trial comparing open and laparoscopic approaches. Surg Endosc 2006;20(12):1831-1834. DOI: 10.1007/s00464-005-0454-5.

14. Al-Rashedy M, Dadibhai M, Shareif A, et al. Laparoscopic gastric bypass for gastric outlet obstruction is associated with smoother, faster recovery and shorter hospital stay compared with open surgery. J Hepatobiliary Pancreat Surg 2005;12(6):474-478. DOI: 10.1007/s00534-005-1013-0.

15. Alam TA, Baines M, Parker MC. The management of gastric outlet obstruction secondary to inoperable cancer. Surg Endosc 2003;17(2):320-323. DOI: 10.1007/s00464-001-9197-0.

16. Kazanjian KK, Reber HA, Hines OJ. Laparoscopic gastrojejunostomy for gastric outlet obstruction in pancreatic cancer. Am Surg 2004;70(10):910-913.

17. Gonzalez R, Lin E, Venkatesh KR, et al. Gastrojejunostomy during laparoscopic gastric bypass: analysis of 3 techniques. Arch Surg 2003;138(2):181-184. DOI: 10.1001/archsurg.138.2.181. 